УДК 37.013:37.014.3+159.9

\title{
ИНКЛЮЗИВНОЕ, ИНТЕГРАТИВНОЕ, ИНТЕГРАЛЬНОЕ ОБРАЗОВАНИЕ В СОВРЕМЕННОМ МИРЕ: ОБЩЕЕ И РАЗЛИЧНОЕ В ПОДХОДАХ.
}

\author{
Абу-Талеб Дарья Викторовна \\ соискатель ученой степени кандидата психологических наук \\ Научный руководитель: Пискарев Павел Михайлович \\ профессор, д.П.н. \\ Институт психологии творчества
}

\begin{abstract}
Аннотация: Современная педагогика, по нашему мнению, с необходимостью движется в сторону индивидуального подхода к образованию, основанному на принципах личностного, контекстного (контекстно-компетентностного), инклюзивного, интегративного (в широком смысле - интегрального) подходов.
\end{abstract}

Для того, чтобы описать различия между инклюзивным, интегративным и интегральным подходами в образовании, необходимо различать инклюзивный и интегративный подходы. Отметим, что вопрос о различении этих подходов - дискуссионный.

Ключевые слова: инклюзивное образование, интегративное образование, интегральное образование, аксиосфера, пссихосемантическое пространство интегрального образования, непрерывное образование, интегральная субординация, интегральная мотивация.

\section{INCLUSIVE, INTEGRATIVE, INTEGRAL EDUCATION IN THE MODERN WORLD: COMMON AND DIFFERENT APPROACHES.}

\section{Abu-Taleb Daria Viktorovna Scientific supervisor: Piskarev Pavel Mikhailovich}

\footnotetext{
Abstract: Modern pedagogy, in our opinion, is necessarily moving towards an individual approach to education based on the principles of personal, contextual (context-competence), inclusive, integrative (in the broad sense - integral) approaches. In order to describe the differences between inclusive, integrative and 


\section{ОБРАЗОВАТЕЛЬНЫЕ ТЕХНОЛОГИИ \\ В СОВРЕМЕННОМ УЧЕБНО-ВОСПИТАТЕЛЬНОМ ПРОСТРАНСТВЕ}

integral approaches in education, it is necessary to distinguish between inclusive and integrative approaches. It should be noted that the question of distinguishing these approaches is debatable.

Key words: inclusive education, integrative education, integral education, axiosphere, psychosemantic space of integral education, continuing education, integral subordination, integral motivation.

В статье "Интегрированное и инклюзивное образование для ребенка с ограниченными возможностями здоровья" [6] написано:

“Отличие интеграции от инклюзии в образовании заключается в следующем: Интегративное образование подразумевает обеспечение доступности обычной образовательной программы внутри школьных стен для обучающихся с OB3, прежде всего, - с ограниченными возможностями передвижения. Инклюзивное образование - создание и поддержание условий для совместного обучения в классе обычных детей и детей с ООП по разным образовательным программам. Инклюзия - это процесс реального включения инвалидов в активную общественную жизнь и в одинаковой степени необходима для всех членов общества" [6].

В статье "Инклюзивное образование: технологии формирования у детей навыков социального взаимодействия" указано следующее [13, с.57]: “В контексте педагогических технологий рассмотрим те, которые можно было бы назвать инклюзивными или интегративными. Большинство из них, однако, может быть использовано не только в рамках образовательного процесса, но и в любых социальных программах. К технологиям инклюзивного образования мы относим те технологии, которые ведут к созданию наиболее полноценного процесса включения детей с ОВ3 в образовательный процесс без ущерба для остальных детей, а также способствуют развитию принимающей среды. Если выделить технологии, направленные в основном на развитие ребёнка с ОВ3, коррекцию его нарушений и предполагающие индивидуальную работу с ребёнком, то их мы можем условно назвать интегративными. Подчеркнем, что интегративные технологии не предполагают такой подготовки среды, как инклюзивные технологии. При всей сложности включения детей с ОВ3 в образовательный процесс, инклюзивные практики и технологии позволяют сделать его более индивидуализированным”.

Итак, мы полагаем, что “особые образовательные потребности”, о которых пишут теоретики инклюзивного образования, существуют у каждого 


\section{ОБРАЗОВАТЕЛЬНЫЕ ТЕХНОЛОГИИ \\ В СОВРЕМЕННОМ УЧЕБНО-ВОСПИТАТЕЛЬНОМ ПРОСТРАНСТВЕ}

ребенка, поскольку не бывает двух одинаковых детей, с одинаковым темпераментом, интересами, способностями, талантами, идентичным социально-культурным контекстом существования. Думается, что в современном мире корректно говорить не столько об “особых детях”, сколько о необходимости особого педагогического подхода к каждому ребенку (поскольку у каждого ребенка существуют те или иные личностные особенности и особые образовательные потребности).

В статье Е.Г. Огольцовой [11], посвященной развитию инклюзивного образования в России, находим похожее: “Инклюзивное образование развивает методологию, направленную на детей, признающую, что все дети - индивидуумы с различными потребностями в обучении. Оно разрабатывает подход к преподаванию и обучению. В его основе - 8 основополагающих принципов: - Ценность человека не зависит от его способностей и достижений; - Каждый человек способен чувствовать и думать; - Каждый человек имеет право на общение и на то, чтобы быть услышанным; - Все люди нуждаются друг в друге; - Подлинное образование может осуществляться только в контексте реальных взаимоотношений; - Все люди нуждаются в поддержке и дружбе ровесников; - Для всех обучающихся достижение прогресса скорее может быть в том, что они могут делать, чем в том, что не могут; - Разнообразие усиливает все стороны жизни человека" [11, c. 250]. Каждый из этих принципов применим и к интегральному образованию.

В статье “Трансатлантическая беседа об инклюзивном образовании" [15] находим мысли, значимые в контексте нашей работы: об идеологических основах инклюзивного образования, о конституционных его основах, а также о том, как в инклюзивном образовании следует воспринимать учеников “с особыми потребностями”. “Инклюзивное образование политически основано, исторически укоренилось и социально сконструировано и пересекается с культурой и социальным развитием. В инклюзивном образовании школы рассматриваются как площадки для решения вопросов равенства и социальной справедливости. Идеи свободы и равенства унаследованы от Французской революции, а инклюзивное образование опирается на конституционное право на получение образования, а также на принципы социальной справедливости. Как отмечают Топпинг и Мэлони [14], законодательство, касающееся равных возможностей, не означает, что каждый студент или ученик требует одинакового отношения, но «скорее, это 


\section{ОБРАЗОВАТЕЛЬНЫЕ ТЕХНОЛОГИИ В СОВРЕМЕННОМ УЧЕБНО-ВОСПИТАТЕЛЬНОМ ПРОСТРАНСТВЕ}

подразумевает то, что к разным людям необходимо относиться по-разному, чтобы у них были равные возможности для максимизации своего потенциала» $[14$, P. 2].

Этот педагогический подход делает упор на развитие сильных сторон и удовлетворение конкретных потребностей человека, а не на патологизации специального образования и категоризации определенной группы учащихся в соответствии с «псевдодиагностическими ярлыками» [14, Р. 3]. Инклюзивное образование следует рассматривать в более широком контексте социальных проблем, связанных с социально-экономическим статусом, расой, полом, культурой и другими факторами, которые оказываются причинами маргинализации и изоляции людей. С этой точки зрения создание подходящей среды обучения для всех детей в школах по месту жительства становится сложным и противоречивым процессом. Мы можем разработать и принять законодательство и политику в поддержку этой идеалистической концепции, но реализация этой концепции очень проблематична [15, Р. 276]”.

В мире концепцию инклюзивного образования поддерживает и развивает ЮНИСЕФ [5]: “Инклюзивное образование - наиболее эффективный путь, помогающий дать всем детям справедливый равный шанс пойти в школу, учиться и развивать их способности, которые нуждаются в росте и развитии. Инклюзивное образование предполагает единые классы и школы для всех детей. Это предполагает также реальные возможности учебы для социальных групп, которые в рамках традиционного образования были исключены: не только “особые” дети или дети с инвалидностью, но и дети мигрантов или представителей национальных меньшинств, говорящие на иностранных языках". Инклюзивная образовательная система ценит уникальный вклад, который ученики разных происхождений приносят в класс и в образовательный процесс, позволяя представителям различных групп расти бок о бок и развиваться на благо всех". Эти базовые ценности инклюзивного образования также родственны интегральному образованию. В сущности, объединение представителей разрозненных социальных групп в единой образовательной среде и одном образовательном процессе - один из принципов интегрального образования.

В статье Г.Т. Пономаревой “Инклюзивное образование в России” [12] находим описание трудностей инклюзивного образования (в том числе подготовки специалистов в области инклюзивного образования) и пути их 


\section{ОБРАЗОВАТЕЛЬНЫЕ ТЕХНОЛОГИИ В СОВРЕМЕННОМ УЧЕБНО-ВОСПИТАТЕЛЬНОМ ПРОСТРАНСТВЕ}

решения. Некоторые из описанных аспектов применимы и к интегральному образованию, перечислим их ниже:

1. Дефицит квалифицированных кадров. Не каждый педагог обладает компетенциями, знаниями, опытом, необходимыми для работы в системе интегрального образования. Говоря о квалификации и компетенциях преподавателей и других специалистов, приведем также перечень критериев для отбора и подготовки специалистов для работы в системе интегративного образования [8, с.57]:

- глубокая контекстная специализация в конкретных науках;

- свободное ориентирование в общекультурных областях знания;

- серьезная психолого-педагогическая подготовка;

• владение методологическим аппаратом и коммуникативной техникой;

• высокий креативный и нравственный потенциал.

Мы, в свою очередь, добавим к этому перечню критериев необходимой квалификации специалистов в области интегрального образования, квалификацию в области помогающих практик (психологии, коучинга, социальной работы). Так, С.Г. Литке пишет о социально-психологической компетентности как интегрального явления в континууме модернизации образования [7].

Также одним из критериев необходимой квалификации специалистов в области интегрального образования можно, опираясь на статью теоретика и практика интегрального образования А.В. Непомнящего [10], назвать ноосферное мировоззрение (в противовес техносферному) как гуманистическое мировоззрение, интегративное видение всех значимых аспектов существования человека и человечества в период глобализации и информатизации.

2. Недостаточный уровень обучения иностранным языкам, что мешает включению отдельных образовательных сообществ в интегральное общемировое образовательное пространство (один из принципов интегрального образования). Также это противоречит принципу непрерывного образования (фундаментальная основа интегрального образования, которая будет рассмотрена ниже во всем множестве ее измерений), в контексте не только индивидуально-личностного аспекта непрерывности, но и в контексте глобального, общемирового аспекта непрерывности - взаимодействия образовательных учреждений разных стран, обучение опыту интегрального, интегративного, инклюзивного образования в других странах. По мнению 


\section{ОБРАЗОВАТЕЛЬНЫЕ ТЕХНОЛОГИИ В СОВРЕМЕННОМ УЧЕБНО-ВОСПИТАТЕЛЬНОМ ПРОСТРАНСТВЕ}

Г.Т. Пономаревой, современные требования к подготовке специалистов в области интегрального образования включают в себя обучение на иностранном языке [12].

3. Недостаточное количество дисциплин по выбору в учебном плане. Увеличение количества дисциплин по выбору позволит учащимся реализовать собственные интересы, раскрыть и развить способности, выбрать направление своего дальнейшего развития.

4. Большая очная (аудиторная) нагрузка в ущерб самостоятельной, в том числе командной, работе. Мы полагаем, что работа в команде и командное взаимодействие - важный аспект обучения в рамках интегрального образования, поскольку развивает способности учащихся к сотрудничеству, взаимопомощи, анализу умений, талантов, слабых и сильных сторон (собственных и друг друга), распределению обязанностей, горизонтальному взаимодействию, ненасильственному общению, предотвращению, медиации и разрешению конфликтов. Кроме того, самостоятельная и командная работа развивает способности учащихся к поиску и анализу информации, нахождению путей решения задач. “Самостоятельные работы” на занятиях как форма контроля успеваемости учащихся - также устаревший, на наш взгляд, формат самостоятельной работы. Актуальный формат - самостоятельная познавательная, проектная, научная деятельность.

5. Устаревшие технологии образования, субъект-объектный подход в образовании. Лекционный формат (однонаправленной передачи знаний) в инклюзивном и интегральном образовании с необходимостью сочетается с другими форматами работы: дискуссиями (и дискуссионными клубами), мозговым штурмом, деловыми играми, тренингами и т.д.

Можно добавить и другие значимые проблемы актуального образования, которые преодолеваются в интегральном образовании. К таким проблемам можно отнести “недружелюбие" физического образовательного пространства (аспект, описанный в концепции интегративного образования, как образовательной среды, в которую включены люди с физической инвалидностью). По нашему мнению, интегральное физическое, материальное пространство в интегральном образовательном учреждении должно быть “дружелюбным” к любому участнику. В этом смысле мы полагаем, что каждый человек (в пространстве интегрального образования) обладает собственными уникальными особенностями и потребностями, в том числе физическими. Поэтому интегральное образовательное пространство 


\section{ОБРАЗОВАТЕЛЬНЫЕ ТЕХНОЛОГИИ В СОВРЕМЕННОМ УЧЕБНО-ВОСПИТАТЕЛЬНОМ ПРОСТРАНСТВЕ}

учитывает, как и интегративное, потребности учащихся и преподавателей с инвалидностью, но не только; оно создано с тем, чтобы реализовывать и другие особенные потребности участников: в движении и другой физической нагрузке, в отдыхе, покое и расслаблении, в регулярном питании с учетом индивидуальной диеты, в уединении, в самостоятельной учебе и другой познавательной деятельности, в том числе научной, в творческой деятельности, в развлечении, в игре, в межличностном и межгрупповом общении, в медицинской помощи и т.д.

Еще одним важным параметром, отличающим интегральное образование от инклюзивного и интегративного (при всей схожести и родственности их принципов), является уникальная этика, формирующая ценностно-нормативное пространство интегрального образования (которое мы называем “аксиосферой интегрального образования” [1, с. 93.], а также “психосемантическим пространством интегрального образования" [4]). Отдельные вопросы этики как аспекта образования рассмотрены, например, в концепции “интегральной этики” В.Н. Назарова и Е.Д. Мелешко [9], которая предполагает обучение этике в ее связи с другими родственными дисциплинами в высшей школе. Думается, что средняя школа как пространство интегрального образования также нуждается в преподавании этики, в ее сочетании с другими дисциплинами социально-философского спектра: истории и теории философии, социальной философии, культурологии, религиоведения, социологии, психологии и социальной психологии, и др. Интегральный аспект в данном смысле раскрывается в демонстрации учащимся взаимосвязанности перечисленных дисциплин и их значимых принципов, а также их прикладного аспекта - возможности использования в повседневной жизни и деятельности.

Итак, говоря о различиях в принципах инклюзивного и интегрального, интегративного и интегрального образования, заметим, что:

1. Данные различия слабо рассмотрены в современном пространстве научно-практической мысли. Идея интегрального образования в современной России также слабо концептуализирована; концептуализации данной идеи и посвящена, в частности, наша работа.

2. Мы полагаем, что аксиологический фундамент и основные принципы инклюзивного образования входят также в фундаментальные принципы интегрального образования, а отдельные идеи интегративного образования 


\section{ОБРАЗОВАТЕЛЬНЫЕ ТЕХНОЛОГИИ В СОВРЕМЕННОМ УЧЕБНО-ВОСПИТАТЕЛЬНОМ ПРОСТРАНСТВЕ}

(если понимать его как образование, в которое включены люди с физической инвалидностью) полностью совпадают с идеями интегрального образования.

3. При этом интегральное образование от интегративного и инклюзивного отличается, прежде всего, наличием в аксиосфере интегрального образования идей о непрерывности образования (во всем множестве значимых аспектов этой непрерывности), “интегральной субординации" (авторский термин, который мы раскроем ниже) и связанного c ней особого межпоколенного взаимодействия в интегральном образовательном пространстве [3]; “интегральной мотивации” (как особенности формирования эмоционально-волевой сферы участников интегрального образования, а также - особым коммуникативным (когнитивнокоммуникативным) пространством интегрального образования [2].

\section{Список литературы}

1. Абу-Талеб Д.В. Агональность в интегральном образовании // Педагогика и психология в современном мире: теоретические и практические исследования. сб. ст. по материалам XLVII междунар. науч.-практ. конф. - № 5 (47). - М., Изд. «Интернаука», 2021. - 142 с.

2. Абу-Талеб Д.В. Коммуникативно-когнитивные пространства в эпоху метамодерна // Вестник интегративной психологии // Журнал для психологов. Вып. 21. /Под ред. В.В.Козлова. - Ярославль: МАПН, 2020. - 478 с. - С. 29-34

3. Абу-Талеб Д.В., Межпоколенная коммуникация в контексте современного образования личности // Педагогика и психология в современном мире: теоретические и практические исследования: сб. ст. по материалам XLVII междунар. науч.-практ. конф. —№ 5(47). -М., Изд. «Интернаука», 2021. -142c.

4. Абу-Талеб Д.В. Эмоционально-волевая сфера и ее развитие в интегральном образовании // Современная наука: актуальные проблемы теории и практики. Серия: Познание. - 2021. - №7

5. Инклюзивное образование: [Электронный ресурс] - Режим доступа: https://www.unicef.org/education/inclusive-education (дата обращения: 28.02.2021)

6. Интегрированное и инклюзивное образование для ребенка с ограниченными возможностями здоровья. - [Электронный источник]. - Режим 
доступа: https://mbouk.edumsko.ru/activity/fgos/post/260607 (дата обращения: 20.06.2021)

7. Литке, С.Г. Социально-психологическая компетентность как интегральное явление в континууме модернизации высшего профессионального образования / С.Г. Литке // Методология современной психологии. - 2014. - № 4. - С. 117-122.

8. Маренков А.И., Жаравина Ю.А. Интегративное образование // Молочнохозяйственный вестник. - 2011. - №1 - С.57

9. Назаров В.Н. Этическое образование в России: проект "интегральной" этики / В.Н. Назаров, Е.Д. Мелешко // Вестник Российского гуманитарного научного фонда. - 2005. - № 3(40). - С. 98-107

10. Непомнящий А.В. Пути развития ноосферного мировоззрения в системе интегрального образования / А.В. Непомнящий // Культура. Наука. Интеграция. - 2016. - № 4(36). - С. 11-19

11. Огольцова Е.Г. Развитие инклюзивного образования в России / Е.Г. Огольцова, А.Э. Тимохина, Е.А. Сергеева. - Текст : непосредственный // Молодой ученый. — 2017. — № 50 (184). - С. 249-252

12. Пономарева Г.Т. Инклюзивное образование в России / Г.Т. Пономарева. - Текст : непосредственный // Педагогика высшей школы. — 2017. — № 2 (8). — С. 59-62

13. Самсонова Е.В., Рыскина В.Л. Инклюзивное образование: технологии формирования у детей навыков социального взаимодействия // Социальная педагогика. 2014. №1., 128 с.

14. Topping, K. Maloney, S. The Routledge Falmer Reader in Inclusive Education. - London: Routledge Falmer. - 280 p.

15. Schneider C. Harkins M. J. Transatlantic Conversations about Inclusive Education: France and Nova Scotia // Research in Comparative and International Education. - 2009. - Vol. 4. - № 3. - P. 276-288 